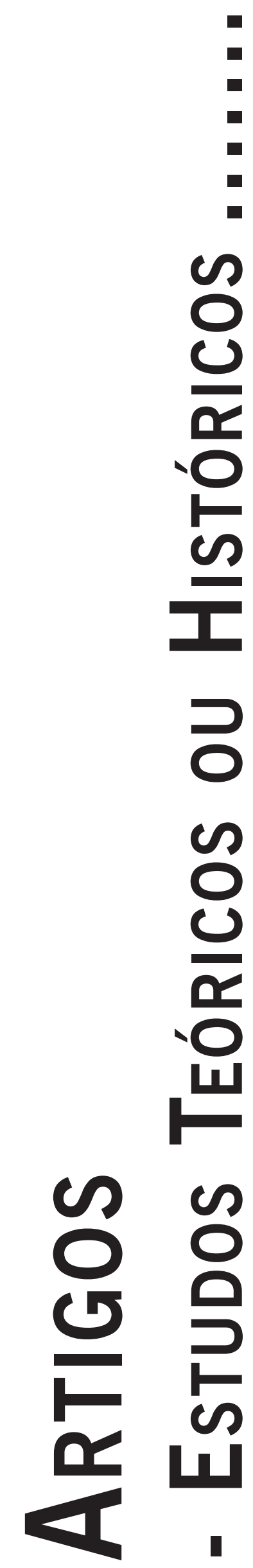




\title{
PETER SCHMID E A ALTERIDADE RADICAL: RETOMANDO O DIÁLOGO ENTRE ROGERS E LÉVINAS
}

\author{
Peter Schmid And Radical Alterity: Reapproaching the Dialogue Between Rogers and Lévinas
}

Peter Schmid y la Alteridad Radical: Retomando el Diálogo entre Rogers y Lévinas

Iago Cavalcante Araújo

José CÉLIO FREIRE

\begin{abstract}
Resumo: A Abordagem Centrada na Pessoa (ACP), fundada por Carl Rogers, só pode ser justificada a partir de uma ética e não como aplicação de técnicas e conhecimentos. Entretanto, a ACP, a princípio, negligencia a alteridade radical postulada por Lévinas. Este Outro não é figura tão cara às psicologias como aparenta ser. O Outro levinasiano precede e transcende ao Eu, não sendo totalizável nem inteiramente compreensível, ele apresenta a dimensão do estranho na experiência psicológica. Peter Schmid, no entanto, concebe a ética como primeira questão a ser pensada quando se trata da ACP, quer de sua teoria, quer de sua prática e estabelece um profícuo diálogo com a filosofia levinasiana. Este trabalho apresenta as contribuições de Peter Schmid à Psicologia rogeriana. Concluiu-se que, ao fazer releituras dos principais conceitos da ACP, Schmid apresenta uma nova forma de lidar com a alteridade no arcabouço da ACP.
\end{abstract}

Palavras-Chaves: Abordagem centrada na pessoa; Ética; Peter Schmid; Emmanuel Lévinas.

Abstract: The Person Centered Approach (PCA), founded by Carl Rogers, can only be justified by ethics and not as an application of skills and knowledge. However, PCA, at first, neglects the radical alterity postulated by Lévinas. This Other is not an expressive figure to psychologies as seems to be. The Levinasian Other is precedent and transcendent to the I; not being possible to totalize and understand it fully; it shows the dimension of the strange in the psychological experience. On the other hand, Peter Schmid conceives that ethics is the first issue to be considered when it comes to PCA, either its theory or its practice; establishes a fruitful dialogue with the Levinasian philosophy. This paper presents the contributions of Peter Schmid to the Rogerian psychology. It was found that Schmid shows a new way of dealing with the alterity within the framework of the Rogerian approach.

Keywords: Person centred approach; Ethics; Peter Schmid; Emmanuel Lévinas.

Resumen: El abordaje centrado en la persona (ACP), fundado por Carl Rogers, solo puede ser justificado a partir de una ética y no como aplicación de técnicas y conocimientos. Sin embargo, la ACP abandona, en principio, a la alteridad radical postulada por Lévinas. Este Otro no es una figura tan cara a las psicologías como aparenta ser. El Otro levinasiano precede y trasciende al yo, no siendo totalizable ni enteramente comprensible; él, representa la dimensión de lo extraño en la experiencia psicológica. Por otro lado, Peter Schmid, concibe a la ética como primera cuestión a ser pensada cuando se trata del ACP, tanto con su teoría como con su práctica, estableciendo un fructífero diálogo con la filosofía levinasiana. Este trabajo presenta las contribuciones de Peter Schimid a la Psicologia Rogeriana. Se concluye que, al hacer relecturas de los principales conceptos del ACP, Schmid presenta una nueva forma de relacionarse con la alteridad en las bases teóricas fundamentales del ACP.

Palabras claves: Abordaje centrado en la persona; Ética; Peter Schmid; Emmanuel Lévinas.

\section{Introdução}

Desde os seus primeiros anos, entre o fim do século XIX e o começo do século XX, a Psicologia surgiu como uma prática de cuidado e controle sobre os indivíduos. A Modernidade, que constituiu a demanda de um controle cada vez mais íntimo das pessoas, também foi a responsável pela criação do sujeito psicológico e, consequentemente, da própria Psicologia (Figueiredo, 1996). Este indivíduo psicológico surgiu a partir da falha do projeto epistemológico da modernidade, quando o humano não é capaz de autoconhecer-se suficientemente para daí conhecer o mundo. A ciência psicológica tornou-se, então, responsável pelo cuidado com essa dimensão estranha da subjetividade humana, que foi considerada como dejeto expurgado pela ciência moderna. Desde então, o trabalho psicológico tratou de ajustar comportamentos que eram considerados desviantes destes padrões.

Como contraponto às práticas de ajustamento e centradas no problema, as psicologias humanistas, que compuseram - junto às psicologias fenomenológicas, existenciais e experienciais - a terceira força da Psicologia, surgiram dando destaque ao que é propriamente humano, isto é, à sua capacidade de significar e ressignificar o mundo da vida em que está inserido, sendo capaz de superar qualquer determinismo. Estas psicologias, em contraposição ao objetivismo e racionalismo empregado pelas práticas referidas acima, trabalham com sensações e sentidos 
vividos e atribuídos pelo humano, aceitando que o sujeito é linguagem, um ser capaz de dar sentido ao corpo de experiências que vive na relação com o mundo e as pessoas (Amatuzzi, 2001).

Apesar do caráter sedutor de tal empreitada, no sentido da possibilidade de ter para si o domínio da vida, Freire (2002), ao discutir sobre a ética impregnada nas psicologias, postula que estas ainda estão vinculadas a um modelo de controle e poder, pois, configuram-se como forma de usurpação do lugar do Outro, daquilo que há de estranho e indomável na vida humana. Mais especificamente, no que tange à Abordagem Centrada na Pessoa (ACP), proposta por Carl Rogers, forjada no contexto do início da Psicologia estadunidense, caracterizada pelo tecnicismo e racionalismo, recoloca-se no indivíduo o centro avaliativo de todo o processo psicoterápico, preconizando a sua liberdade e autonomia. Nesse referencial, proporcionou-se maior participação do paciente (agora cliente) em seu processo terapêutico e também um novo valor para ele, dentro e fora do setting psicoterapêutico; ele, então, poderia ser quem verdadeiramente é, tornando-se plenamente uma pessoa (Rogers, 1961/2009). Além disso, a proposta rogeriana procurou dar novo valor à pessoa dentro da relação terapêutica, enfatizando, também, o terapeuta como ser humano no contexto da terapia. Isto implica que o profissional deve utilizar-se de seu referencial teórico e valorativo para fomentar a autonomia e responsabilidade do cliente na relação psicoterapêutica e, a partir desta, em sua experiência no mundo. $\mathrm{O}$ psicoterapeuta deve buscar desfazer-se de qualquer pretenso domínio sobre o outro, mesmo que isto lhe seja requerido pelo próprio cliente. Quem melhor sabe sobre o cliente é ele mesmo (Rogers, 1951/1975). Rogers postulou a importância das relações pessoais para o desenvolvimento do ser humano, chegando a formular uma teoria das relações humanas (Rogers \& Kinget, 1959/1977). Tais concepções alastraram-se também por outros campos de atuação, fazendo com que as contribuições de Carl Rogers ficassem famosas na área educacional, organizacional, (da Psicologia) de Grupos, da mediação de conflitos, entre outras. A respeito destas contribuições, Amatuzzi (2010) argumenta que são de ordem eminentemente ética, muito mais do que técnica, de forma que a ACP apenas pode ser justificada a partir de um conjunto de valores e de uma ética, e não como uma aplicação de técnicas e de conhecimentos.

A proposta ética da ACP foi considerada e criticada por Freire (1989) a partir de um viés materialista histórico e dialético. Naquele momento, ele afirmou que o homem rogeriano não é um ser moral por estar apartado da consciência histórica da necessidade e transformação da realidade. Mais adiante, a ACP foi novamente criticada por Freire (2002), a partir da ética da alteridade radical, de Emmanuel Lévinas. Ele postulou não haver lugar para a alteridade radical levinasiana na ACP, bem como em outras três perspectivas em psicologia (Daseinsanalyse, Psicogenética e Análise Experimental do Comportamento), pois, nela, há a predominância do eu (self), do mesmo e do idêntico em detrimento do Outramente-que-ser, do estranho e da diferença. Mesmo que Rogers se refira ao outro, ele está sempre a serviço e ao alcance do Eu, para ser compreendido, totalizado e equiparado: é ainda um alter-ego, um outro eu (Freire, 2002). A ética da ACP, em sua relação com a ética levinasiana, foi novamente contemplada nas leituras críticas de Vieira e Freire (2006), que procuraram apontar possíveis aberturas da abordagem à alteridade radical trazida por Lévinas (1961/2008). Mesmo ali, o texto apontou para limitações encontradas na obra de Rogers que poderiam ser rediscutidas em busca de uma relação menos alérgica com o Outro levinasiano.

O desenvolvimento de tais estudos, que procuram reconsiderar a ética desta abordagem, apresentou-nos a obra de Peter F. Schmid, psicólogo austríaco professor da Sigmund Freud Private Universität Wien, que tem trabalhado acerca da alteridade na ACP, estabelecendo diálogos entre a teoria de Rogers e as filosofias dialógicas, onde ele “enquadra” o trabalho de Emmanuel Lévinas (1961/2008).

Em uma rápida pesquisa sobre a bibliografia de Peter Schmid, é possível observar que aponta grande interesse pela Psicologia, a Teologia e as Artes. O austríaco tem vasta formação no campo da Teologia, principalmente católica, com graduação e pós-graduação (mestrado e doutorado) na área, além de formação em Psicologia e Sociologia. Ao mesmo tempo, Schmid apresenta uma importante atuação na clínica da Abordagem Centrada na Pessoa e, ao longo do tempo, vem desenvolvendo um trabalho com parceiros ao redor do mundo, com os quais apresentou publicações decorrentes destas parcerias. Foi também fundador, junto a outros psicólogos da abordagem, de importantes organizações e associações da ACP, como a Person Centered Association (PAC), a Network of the European Associations for Person-Centered and Experiential Psychotherapy and Counselling (NEAPCEPC) e a World Association for Person-Centered and Experiential Psychotherapy and Counselling (WAPCEPC). Tem importante participação como editor de revistas acadêmicas de divulgação mundial, como a revista Person Centered and Experiential Psychotherapy, da WAPCEPC, o British Journal of Guidance \& Counselling, de Londres e a A Pessoa como Centro, revista de estudos rogerianos de Lisboa.

Teve Carl Rogers como importante parceiro de trabalho nos anos de 1981 e 1984, de forma que Schmid conviveu com um Rogers diferente daquele que se pode contemplar em algumas sistematizações e artigos do início e meio de sua trajetória, se considerarmos as fases de seu pensamento (Cury, 1987; Moreira, 2007, 2010a; Holanda, 1998; Castelo Branco, 2010). Mesmo que não se possa dizer que é um Carl Rogers totalmente diferente daquele do início de seus trabalhos, é preciso afirmar que, na década de 1980, ele estava voltado principalmente para o trabalho com grandes grupos, afastado dos trabalhos acadêmicos e mais próximo de experiências místicas (Rogers, 1980/1983). 
Para Schmid (1998b), ainda, Emmanuel Lévinas é um pensador de muita importância, que ainda está para ser descoberto pela ACP. Schmid considera que a mudança feita por Lévinas no campo da Filosofia se equipara àquela feita por Rogers na Psicologia. Assim, a ACP mantém importantes portas de diálogo com a filosofia de Emmnuel Lévinas (1961/2008). Segundo Vieira \& Freire (2006), Vieira (2009) e Schmid (1998a), desde o início de sua obra, Carl Rogers estabeleceu uma virada de paradigma, colocando a pessoa do cliente como prioridade no tratamento psicológico, em detrimento de preconcepções nosológicas, por exemplo. Desta forma, Schmid (1998a) afirma que o Outro, em sua alteridade, é a verdadeira questão para a ACP, não a teorização ou a prática da abordagem. Schmid (2001a) considera que Carl Rogers teria preparado diversos caminhos em direção a uma saída da egologia rumo a uma dimensão alteritária e muitos deles ainda estão à espera de serem concretizados.

A partir de uma leitura de Schmid (1998a, 2001a; 2006; 2008), compreendemos que a obra rogeriana apresenta certa ambiguidade na lida com a diferença e com o Outro, porque, se, por um lado, busca atender à experiência humana em seu caráter singular e à pessoa entrelaçada nas relações sociais, por outro, a abordagem rogeriana também tem sido responsável por submeter todo o corpo de experiências com a alteridade ao crivo do sujeito autocentrado. Nesse sentido, a figura de Schmid (2001a) surge como elemento importante para repensar a postura da ACP no trato com a alteridade, pois ele tanto reconhece limitações no texto rogeriano quanto oferece, também, alternativas a este, possibilitando outro modo de lidar com o Outro e aproximando a ACP da ética levinasiana.

\section{A Ética Levinasiana}

Lévinas é um pensador franco-lituano que fez da experiência do holocausto judeu, na Segunda Guerra Mundial, o mote para compor todo um pensamento crítico à filosofia ocidental (Haddock-Lobo, 2006). Como judeu, Lévinas perdeu boa parte de sua família no holocausto: sua esposa e os filhos só sobreviveram por terem se escondido na casa de amigos. Ele mesmo escapou porque atuou, como intérprete e tradutor, nos campos de concentração, pois era alguém que poderia ser "melhor aproveitado" (Poirié, 2007).

A filosofia de Lévinas concebe que a ética, isto é, a relação com o Outro como ente, é anterior à ontologia, já que esta resume a alteridade ao mesmo, ao ser. Assim, Lévinas (1961/2008) concebe que a relação com o Outro precede a concepção do $\mathrm{Eu}$, que se forma, justamente, como resistência à exterioridade. A subjetividade é separação que permite, também, uma forma de lidar com o Outro, na qual "o papel principal do psiquismo não consiste de facto em refletir apenas o ser. É já uma maneira de ser, a resistência à totalidade" (Lévinas, 1961/2008, p. 41, grifos do autor).
Em sua separação do Outro, este Eu vive para além de uma relação dual, em que ele possa se identificar por oposição. A relação que o Mesmo e o Outro mantém não é de reciprocidade nem de dualidade. Se assim fosse, ambos estariam novamente inseridos em uma totalidade. O Eu, em sua existência, mantém-se como autossuficiente, um Eu que Lévinas (1961/2008) chama ateu ${ }^{1}$. Liga todas as coisas a si mesmo e, a cada segundo, está a (re)encontrar-se nas coisas, um ser intransitivo, como esclarece Santos (2007, p. 32): “[...] ele descobre sua intransitividade radical: pois, se pode realizar todos os intercâmbios possíveis com o outro, o eu não pode trocar de ser com o outro; não pode ser outro, e vice-versa. Sob a vigência do verbo ser, o eu faz a experiência de sua solidão [...]”.

Portanto, está também preso a si mesmo, e por mais distante que possa ir, acaba levando-se a todos os lugares. Outra característica do ser, em sua pureza, é a impessoalidade ou indiferença, sua não escolha em ser: "Ser não me encontra, 'choca-se' comigo. Ser é achar-se lançado por ninguém para cumprir a pena perpétua de ser si mesmo" (Santos, 2007, p. 35, grifos do autor). Estas características colocam o ser, por si mesmo, em um mal de ser. Esta angústia empurra-o, desde o princípio, para fora, em uma evasão. É preciso que ele venha ao encontro com o mundo e com o Outro, como uma espécie de salvação deste mal.

A subjetividade encontrada em Lévinas não ocorre segundo uma soberania por parte do sujeito; seria melhor que a considerássemos como sujeitada às relações que mantém com o mundo. É uma subjetividade traumática porque se dá no encontro e rompimentos que o Outro produz sobre esta. Desta feita,

A subjetividade pode ser vista como contínua relação de vir a ser, mas que nunca pára no ser, relação que não cessa com o seu devir, relação que pode fazer com que a subjetividade se torne substituição, substituição que não é termo, mas processo sem fim de exposição ao próximo. (Pivatto, 2003, p. 191)

Lévinas (1982/2007) afirma, ainda, que o movimento do Eu em direção ao Outro pode ser descrito como a carícia, que toca sem tocar, como um gesto nunca satisfeito e que se alimenta da própria fome. É um caminho infinito. Assim é a compreensão de Lévinas: o movimento que vai do Eu a Outrem é fundamentado em um desejo que, ao contrário do que comumente se compreende, não provém de uma falta ou necessidade do sujeito, mas da altura e do excesso do Outro em relação a este. Para Lévinas (1961/2008), a relação Eu-Tu, de Buber (1979), se encontra no âmbito do eros, uma relação que é intimidade, mas, também, distanciamento. Entretanto, para Lévinas, esta forma de relação com o outro ainda guarda sua

\footnotetext{
O termo aqui não adquire conotação de descrença em uma divindade, mas se refere ao modo como o sujeito se mantém no mundo, de maneira independente, não mantendo qualquer compromisso aparente com os Outros que mantém a sua vida.
} 
reciprocidade, no sentido de que o Eu se encontra ainda ligado ao prazer de amar outrem.

O outro levinasiano é de uma natureza diferente da minha, não faz par comigo, não posso tocá-lo, nem tematizá-lo sem que, assim, perca a sua alteridade de vista. Não se trata de um outro Eu, imagem e semelhança deste, mas algo de uma ordem que transcende a minha, escapando a qualquer tentativa de pensamento sobre ele. Para tanto, Lévinas (1982/2007) utiliza-se da ideia de infinito como uma forma de referir-se à aproximação entre o Mesmo e o Outro. Nela, aquilo que é pensado será sempre maior que o pensamento. A ideia de infinito

[...] vem, assim, romper com aquela de totalidade. Nesta reina o pensamento do igual, com a busca de que o Outro se torne o Mesmo, e há um saber e verdade absolutos. Naquela implica-se o pensado do desigual e o excesso no ato de pensar, que contém e não-contem paradoxalmente, a presença do Infinito. (Miranda, 2011, p. 17)

A relação que o finito pode manter com o infinito, ou melhor, a expressão do infinito sobre o finito se dá como desejo. Este é resultado de um excesso e não de uma falta por parte do mesmo, pois, se assim o fosse, a relação continuaria sob o domínio da ontologia e do eu. O desejo é sequela da alteridade sobre a subjetividade; refere-se, excepcionalmente, à altitude daquela. A subjetividade configura-se, assim, sempre, como uma resposta a esta diferença. A relação ética para com o Outro se consuma como responsabilidade, de forma que Lévinas (1991/2005) afirma que ser responsável pelo próximo é outro modo, mais grave, de amá-lo; um amor sem eros, sem concupiscência. O próximo, aqui, não deve ser entendido como espacialmente perto, mas como aquele de quem devo me aproximar por responsabilidade. Santos (2007, p. 191) afirma que esta aproximação ocorre por meio da vulnerabilidade.

Na responsabilidade, e somente nela, a distância torna-se proximidade. Aproximar-se de outrem não é negar a distância, mas deixar que este fale e revele-se a partir de sua altura. Portanto, não se trata também de uma descoberta do Outro por parte do Eu, um desvelamento, como uma atitude de retirar o mistério que há na alteridade, mas de uma constante revelação por parte de outrem, um constante enigma a ser revelado e, assim, uma responsabilidade sempre por se concretizar. Isto instaura um devir sobre a relação e a própria subjetividade.

Além disto, o Outro não se apresenta somente como um Tu, mas como um Ele, distante. No rosto de outem, apresenta-se também o terceiro e, com este, toda a humanidade. Lévinas (1961/2008, p. 208) afirma: "A epifania do rosto como rosto abre a humanidade. O rosto na sua nudez apresenta-me a penúria do pobre e do estrangeiro [...]”. O Terceiro, o outro do Outro, quebra a dualidade que poderia existir entre o Eu e outrem. Ele apresenta a humanidade como um todo e traz à tona a justiça porque o Terceiro é um Outro para o Outro e, por isso, não pode ser desmerecido frente a ele. Instaura-se a igualdade entre ambos. Portanto, a relação para com outrem guarda, também, as relações que este mantém com o mundo e seus Outros, de forma que a responsabilidade é radicalizada e extrapolada para além da relação dual.

A Filosofia de Lévinas nos apresentou um sujeito traumatizado, não por sua relação sincrônica e cúmplice para com o Outro, mas por se caracterizar como uma subjetividade que é sempre resposta incessível a outrem. Sua obra nos apresenta outra maneira de lidar com o Outro $\mathrm{e}(\mathrm{m})$ sua alteridade, figura que deveria ser tão cara às psicologias, como profissão de cuidado com o ser humano (Freire, 2002). Veremos agora que Schmid utiliza-se de diversos dos elementos da teorização de Lévinas, alguns de modo sutil, outros com clara referência ao filósofo lituano, oferecendo, assim, uma outra abordagem da alteridade no campo da ACP.

\section{A ACP aos olhos de Peter Schmid}

Peter Schmid desenvolveu importantes contribuições para a teoria e a prática da Abordagem Centrada na Pessoa, fazendo críticas internas à ACP, sem perder o diálogo com outros campos do conhecimento, como a Arte, a Religião e a Filosofia. Sua tentativa é de utilizar-se de caminhos incompletos oferecidos pelo próprio Rogers e trazer implicações de outros pensadores para contribuir no desenvolvimento da ACP. Trata-se de uma forma de trabalhar a disseminação do trabalho de Rogers e da filosofia dialógica, percebendo como esta pode oferecer implicações ao modelo de Psicologia rogeriano. Entre estas implicações, podemos citar a importância da alteridade na constituição e transformação da subjetividade.

Schmid (2000) parte da compreensão de que, para muitos rogerianos, a Abordagem Centrada na Pessoa (ACP) parece ter perdido o seu caráter revolucionário e que parece, até agora, "sobreviver" como uma abordagem complementar a intervenções terapêuticas mais focadas em técnicas (arte-terapia e acupuntura, por exemplo) ou ao lado de abordagens influenciadas pela Gestalt-Terapia, como tem-se visto. Possivelmente, por ter sido parceiro de Rogers nos anos 1980, Schmid se apropriou principalmente de uma perspectiva mais relacional e coletiva da ACP, de forma que chega a propor que os trabalhos com grupos devam ser o foco principal da abordagem. Para ele, toda demanda de tratamento, assim como qualquer transformação psicoterapêutica necessária, se dá principalmente por meio das relações interpessoais, dos grupos em que estamos inseridos. Assim, por considerar o ser humano como radicalmente social, a ACP deve assumir que este é o principal campo de sua terapêutica. Schmid (2000) afirma, ainda, que o essencial da ACP ainda não foi nem mesmo sondado em seu radicalismo, enquanto proposta 
de emancipação humana. O autor, assim, qualifica a proposta de Rogers como dotada de um humanismo radical.

O motivo de Schmid (2000) assim caracterizar a ACP não está bem explicitado nos textos que compuseram os nossos estudos, que se centraram em artigos em língua inglesa de autoria do referido autor. Ao que nos parece, Schmid utiliza-se do termo "radical" para enfatizar o posicionamento que o humanismo toma sobre a pessoa a ser ajudada: naquele momento, não há nada de mais importante do que a pessoa. É também uma indicação de quem ainda quer apostar neste referencial: fortalecer e radicalizar o humanismo rogeriano. Schmid toma esta postura ao considerar que é a radicalização da ACP, seu aprofundamento, que possibilitará seu desenvolvimento, não uma atitude de fuga às críticas levantadas, ou mesmo a mesclagem dela com outras abordagens. Além do mais, supomos que o uso do termo seja uma tentativa de aproximar-se dos termos usados por Lévinas quando este trata da "Alteridade Radical” (Lévinas, 1982/2007).

Desta forma, por meio do contato que o austríaco manteve com Rogers nos anos 1980, fase que Holanda (1998) nomeia de coletiva ou inter-humana, Schmid (2000) entende que é preciso reler e redizer os conceitos básicos da ACP a partir dos desenvolvimentos das últimas fases, que agregam características mais relacionais à proposta rogeriana. A ACP, então, apresenta um caminho de possibilidades ainda não exploradas que podem oferecer novas perspectivas para a sua ação no mundo. A sua preocupação é buscar certa unidade e identidade, a fim de proporcionar diálogos honestos tanto interna quanto externamente (Schmid, 2003). Para Schmid, assim como o próprio nome da ACP indica, a noção de Pessoa é elemento fundamental em sua leitura da Psicologia rogeriana. Schmid leva este elemento às últimas consequências, de forma que, muitas vezes, mesmo utilizando palavras de Rogers, ele parece tratar de algo que não está posto nas letras rogerianas. Exemplo disto é a sua afirmativa de que Rogers não percebeu todo o potencial daquilo que ele mesmo estava propondo (Schmid, 1998a). A tentativa do psicólogo austríaco é justamente a de desenvolver tais potenciais que ele constata no trabalho de Rogers, de fazer um desenvolvimento posterior a Rogers. Isto pode ser percebido como uma forma de dar vazão às demandas e evocação que as palavras rogerianas fazem ao leitor contemporâneo. Ao possibilitarmo-nos fazer outras perguntas ao texto de Rogers, Schmid promove o contato com a alteridade do texto rogeriano, isto é, com a atualidade de seu discurso.

Tendo trabalhado alguns elementos gerais, gostaríamos, agora, de apresentar a apropriação que Schmid faz da teoria de Carl Rogers e da ética de Emmanuel Lévinas, dois principais fundamentos de seus estudos. Além destes, o trabalho de Schmid está fundamentado na Filosofia Dialógica de Martin Buber. Este, entretanto, será tratado somente na medida que se mostrar importante para aprofundar o entendimento das articulações teóricas feitas por Schmid entre as teorias de Rogers e Lévinas.

\section{A (re)leitura ético-dialógica da ACP feita por Peter Schmid}

Schmid (2003) compreende que a abordagem rogeriana entrou em uma fase profundamente relacional, em que a ética se torna imprescindível (Worsley, 2006). Ele, então, analisa os elementos já trabalhados pela ACP a partir das pesquisas e atividades realizadas na última fase do trabalho de Rogers e de outros desenvolvimentos recentes acerca da ACP. Schmid (2003) apoia-se nas filosofias de Lévinas e Buber, concebendo a ética como elemento importante para a atualidade das psicologias e da ACP, mais especificamente. De acordo com uma série de autores (Holanda, 1998; Moreira, 2010a; Vieira \& Freire, 2006; Miranda, 2012; Bezerra \& Bezerra, 2012), é possível distinguir elementos fenomenológicos, existenciais e dialógicos ao longo de toda teoria e prática da Abordagem Centrada na Pessoa e é no rastro destes possíveis desenvolvimentos que se encaixa a leitura que Schmid (2003) faz acerca da ACP.

Para Schmid (2001a), ao trabalhar com a ideia de pessoa, Rogers não percebeu o potencial inscrito nas formulações que ele mesmo propôs, haja vista as diversas surpresas que o psicólogo estadunidense encontrou no decurso de sua trajetória. De fato, ao longo de sua produção, Rogers se referiu a descobertas em que se sentia surpreso com os alcances de sua teoria e prática. Como exemplo disto, podemos indicar: a descoberta de seu modelo de atendimento se tratar de algo completamente novo (Rogers, 1942/1974); a aplicação de seus princípios terapêuticos a outras áreas de atuação, como organizações e escolas, formando a Abordagem Centrada na Pessoa (Rogers, 1977); e a descoberta do caráter político de sua perspectiva (Rogers, 1970/2001). O texto (a teoria, no caso) sempre diz mais do que aquilo que quer e pode dizer. Desta forma, o psicólogo austríaco, de sua parte, recorre a uma antropologia da pessoa para efetuar desenvolvimentos das noções da abordagem rogeriana.

Schmid (1998a) se apropria do termo "pessoa", utilizado por Rogers, para estabelecer um vínculo entre a ACP e as filosofias do diálogo. Segundo Schmid, Rogers não se utilizou da referida palavra em vão. A definição de pessoa implica em um sujeito que tem um caráter tanto substancial quanto relacional; portanto, segundo Schmid (2000), ao axioma da tendência atualizante, deve ser, também, adicionado o da interconectividade, que é um conceito que proporciona, justamente, a dimensão da alteridade na constituição subjetiva, como já mencionamos anteriormente e explicitaremos melhor no decorrer deste trabalho.

Contudo, não é bem esta a noção de sujeito que encontramos em Rogers (1951/1975). Sua concepção está mais vinculada ao pragmatismo e à ideia de organismo. Entretanto, a noção de Schmid possui influência, principalmente, da fenomenologia e da filosofia dialógica, perspectivas que são mais afins à fase experiencial da 
obra Rogers, de acordo com a sistematização exposta por Moreira (2007; 2010a), o que justifica tal aproximação. Com tal compreensão de pessoa, a tendência atualizante não é mais o único axioma da ACP, mas também a relacionalidade/interconectividade (Schmid, 2000; 2008). Isso faz com que se considere na ACP uma tendência passiva e certa vulnerabilidade originária à presença do outro. Para ele, este aspecto, que foi trabalhado por Rogers de forma quase sutil, precisa ser melhor articulado em um novo conceito, da mesma forma como é necessário fazer com as atitudes facilitadoras. Como Rogers (1980/1983) não teorizou o suficiente na "fase coletiva" de sua obra, é preciso, agora, pôr esta dimensão coletiva de forma evidente em toda a teoria rogeriana. Isso se constitui como uma aufhebung, isto é, uma superação por meio da conservação, ou seja, uma transcendência (Schmid, 2001a). Nas palavras de Schmid, a "Presença pode ser entendida como uma 'Aufhebung' das atitudes básicas: elas são preservadas assim como dissolvidas ao ser superadas e transcendidas" (Schmid, 2001a, p. 224, tradução nossa²). A questão é que, em alguns momentos, isso parece ser feito por Schmid, sufocando o Rogers histórico e suas concepções individualistas; nestes momentos, quando, por exemplo, equipara o outro rogeriano ao outro levinasiano sem apresentar as devidas justificativas, sua teoria parece dar um salto sem oferecer bases teóricas que o justifiquem.

Para Schmid (2003), Rogers desde o início de sua obra, estabeleceu uma virada de paradigma, colocando a pessoa do cliente como prioridade no tratamento psicológico, em detrimento de preconcepções nosológicas, por exemplo. Rogers priorizou o relacionamento com o cliente, em vez de técnicas preconcebidas. De fato, apesar de enfatizar os aspectos individuais, Rogers (1942/1974; 1957/1994; 1970/2001; 1961/2009) denotou a importância das relações interpessoais na transformação pessoal, de tal forma que se pode afirmar que a ACP representou uma ética social, muito mais do que um método de trabalho psicoterapêutico, como afirmou Amatuzzi (2010).

Para a mudança de perspectiva que Schmid quer efetuar, a sua maneira de conceber a ACP faz todo sentido. Entretanto, convém destacar, não é esta a forma como está posta em Rogers. Este (Rogers, 1951/1975) focou seu trabalho, principalmente, na mudança da personalidade. Schmid (1998a), no entanto, é responsável por vincular todas as características da ACP a um conceito, ou melhor, a uma ontologia, mesmo que o faça para tentar abandonar uma egologia que foi alvo de críticas a Rogers (Freire, 2002). Em nossa perspectiva, se Schmid (1998b) vai a Buber e Lévinas (1961/2008) em busca de uma saída do ego e de um novo modo de lidar com a alteridade, ao propor outra forma de conceber a pessoa, ele também centraliza toda a sua teorização neste conceito. O engodo deste artifício pode ser contemplado até mesmo nos

\footnotetext{
“"presence' can be understood as an 'Aufhebung' of the basic attitudes: they are preserved as well as dissolved by being superseded and transcended."
}

escritos de Schmid (2012), quando, ao discutir política, concebe as relações sociais apenas como relações pessoais (face a face).

Entretanto, de forma paradoxal, é, justamente, este conceito que possibilita fazer uma releitura da obra rogeriana, compreendendo, de modo mais profícuo, a participação do Outro na constituição da subjetividade humana. Se, em Rogers (1961/2009), vemos uma hiperbolização da autonomia no sujeito, observamos em Schmid (2001a, 2005, 2006) uma ênfase nos aspectos relacionais de forma a contrabalancear esta díade. Assim, se para Rogers (1957/1994) a relação psicoterapêutica é concebida, principalmente, como um elemento clínico e com consequências, sobretudo, para a outra pessoa, o cliente, para Schmid a autorrealização do Eu está diretamente vinculada à realização do Outro: "Diálogo não é consequência de uma experiência, não é cognição, a descoberta da socialidade. Ao contrário, diálogo é fato primário na condição humana, uma ocorrência original ${ }^{3}$ " (Schmid, 2006, p. 247, tradução nossa). São concepções como esta que embasarão as afirmações de Schmid de que a tendência atualizante não pode ser o único axioma para a transformação psicoterapêutica, mas que a ela deve-se adicionar a interconectividade como fator de constituição da pessoa. Trataremos mais acerca disto adiante, quando aprofundarmo-nos nas bases teóricas de Schmid.

Assim, Schmid (1998a) concebe que o Outro é a verdadeira questão para a ACP. Carl Rogers teria preparado diversos caminhos em direção a uma saída da egologia e muitos deles ainda estão à espera de serem concretizados (Schmid, 2000). Por conta desta última afirmação, é possível dizer que o "uso" que Schmid faz da obra de Rogers é paradoxal, pois ora parte do reconhecimento desta limitação, ainda que poucas vezes o diga, ora avança em direção às filosofias de Buber e Lévinas, parecendo ignorar qualquer diferença. Este último aspecto pode se evidenciar em afirmações como: "Uma relação terapêutica, então, como definida por Carl Rogers, é provavelmente a melhor descrição de uma relação de encontro deste tipo na literatura"' (Schmid, 2001a, p. 223, tradução nossa), referindo-se à concepção de encontro, de Buber. Em nossa leitura dos seus textos, sentimos falta de maiores justificativas para tais desenvolvimentos e, em nossa perspectiva, isto pode desconsiderar diferenças conceituais e teóricas que podem acarretar incoerências também na prática da ACP. Portanto, trata-se, agora, de focar na perspectiva do Outro, ou em uma nova abordagem da alteridade na ACP. Neste momento, a figura de Lévinas (1982/2007; 1961/2008) surge como um pensador muito importante. Com Lévinas, toda atividade humana é, em

\footnotetext{
"Dialogue is not a consequence of an experience, not the cognition, the discovery of sociality. On the contrary, dialogue is a primary fact in the human condition, an original occurrence."

4 "A therapeutic relationship, then, as defined by Carl Rogers, is probably the best description of an encounter relationship of this kind in the literature."
} 
si mesma, uma resposta ao Outro, toda ação é dotada de responsabilidade, como veremos no próximo item.

\section{Alteridade radical e ACP na proposta de Peter Schmid}

Quando tratamos das articulações teóricas formuladas por Schmid (1998b; 2005) a respeito de Lévinas (1982/2007; 1961/2008), é preciso que estejamos atentos para o modo como Schmid o faz, pois é com certa raridade que encontramos citações de trechos da obra de Emanuel Lévinas e, quando ocorrem, são frases curtas de textos pouco expressivos do trabalho do filósofo. Apesar disto, Schmid faz referências a Lévinas em todos os seus artigos de língua inglesa a que tivemos acesso. Corroboramos com Worsley (2006) quando ele aponta a importância do trabalho de Schmid em relação à obra de Lévinas, mas também, alerta para a necessidade de uma leitura mais profunda da ética da alteridade radical e uma melhor compreensão das implicações delas em relação à ACP.

Primeiramente, parece-nos que Schmid (1998b) parte das críticas feitas por Buber a Rogers, quando do diálogo entre os dois (Rogers \& Buber, 2008). Buber afirmou que um diálogo, tal como propunha a sua teoria, era inconcebível à abordagem rogeriana porque ela trabalhava segundo uma relação que não é recíproca, pois ambos, cliente e psicoterapeuta, estão na psicoterapia para tratar do primeiro. Schmid (1998b), então, levando em consideração o conhecimento da ACP e a resposta e o trabalho de Rogers, propõe que se trabalhe uma relação psicoterapêutica dialógica em que se leve em consideração justamente o caráter diacrônico da relação. Destarte, Schmid (1998b) vai à busca das implicações da filosofia dialógica de Emmanuel Lévinas para pensar a psicoterapia como encontro e a terapêutica decorrente deste. Portanto, não é do intuito do psicólogo austríaco transpor integralmente os pensamentos levinasianos para o campo da Psicologia. Schmid (2001a) faz toda uma reconceitualização da noção de homem que estava em Rogers (1951/1975] 1961/2009; 1980/1983), ainda que se aproveitando de elementos rogerianos, e o faz de acordo com uma perspectiva dialógica. Na sua concepção de sujeito, como uma pessoa, é possível descrever um ser ambíguo em sua relação com o mundo; singular e soberano sobre o mundo, até mesmo autônomo e autossuficiente e ao mesmo tempo radicalmente e inteiramente comprometido com o mundo (no sentido de estar sujeito a ele). A relacionalidade encontrada em Schmid, tal como a abertura referida em Lévinas (1961/2008), não é negatividade para a subjetividade, mas suplemento ao mesmo tempo intrínseco a ela. Não é à toa que o filósofo, em sua obra Totalidade e Infinito, trata, primeiramente da separação para, então, apontar a relação com o infinito. Neste livro, Lévinas afirma que
É preciso que a interioridade [...] produza um ser absolutamente fechado sobre si próprio, que não tira dialeticamente o seu isolamento da sua oposição a Outrem[...] É preciso, pois, que o encerramento do ser separado seja suficientemente ambíguo para que, por um lado, a interioridade necessária à ideia do infinito permaneça real e não apenas aparente, que o destino do ser interior prossiga num ateísmo egoísta que não é contradito por nada de exterior, e que prossiga sem que o ser, a todos os movimentos de descida na interioridade e ao descer em si, se refira, por um puro jogo da dialética e sob forma de correlação abstracta, à exterioridade. Mas é preciso, por outro lado que na própria interioridade que a fruição escava, se produza uma heteronomia que incite a um outro destino diverso do da complacência animal em si. (Lévinas, 1961/2008, p. 141-142)

Para Schmid (2005), a subjetividade é comunidade desde o seu nascimento; ela é sempre resposta a outrem. Entretanto, apesar de reiterar a primazia do Outro sobre a constituição da subjetividade, como psicólogo clínico mantém o seu olhar nas características da subjetividade. Schmid utiliza uma compreensão levinasiana da subjetividade que o ajuda a promover uma saída de uma egologia, entretanto ele o faz para conceber uma outra noção de homem, a pessoa.

Ainda com referência à primazia da ética sobre a ontologia, é preciso que tragamos à tona uma afirmação de Schmid (2001b), ao apresentar Lévinas, segundo a qual o filósofo franco-lituano apresentou ideias radicais, "[...] efetuando, de algum modo, uma mudança paradigmática similar à de Rogers - propagando profundamente a ideia da primazia do Outro ${ }^{5}$ " (p. 8, tradução nossa). A referida frase pede atenção, pois, a princípio, equipara duas áreas diferentes do saber (Filosofia e Psicologia), além de apontar Rogers sob um aspecto diferente daquele que Freire (2002) nos apresentou. Se o que Schmid quer é apontar para o ineditismo de Rogers nesta virada paradigmática, é necessário entender que ela se deu, principalmente, na Psicologia norte-americana e não constou em uma mudança paradigmática para a ciência psicológica como um todo.

Todavia, a Psicologia rogeriana se caracterizou, realmente, como um rompimento com uma prática que estava centrada nos métodos e no saber do profissional. Rogers (1942/1974) deu primazia ao cliente a quem atendia, possibilitando-lhe o controle e a responsabilidade pelo processo psicoterapêutico. O trabalho do psicoterapeuta consistia, justamente, em compreender o campo fenomenológico do cliente de tal forma que ele se sentisse livre para ser si mesmo. No caso de Lévinas (1961/2008), o filósofo deu um salto em direção ao Outro, procurando

"[...] in some ways executing a similar paradigm change as Rogers profoundly carries forward the idea of the priority of the Other." 
escapar à ontologia. Como nos referimos anteriormente, não era mais o ser que interessava à filosofia levinasiana, mas a alteridade e a relação com ela. Entretanto, e aqui destacamos o perigo da afirmação de Schmid (2001b), o Outro a quem Lévinas (1961/2008) se referia não é alguém palpável e capaz de ser compreendido. Ainda que ambos deem primazia a outra pessoa, eles não estão tratando do mesmo elemento quando se referem à alteridade. A frase torna-se emblemática da forma como Schmid (2001a, 2001b, 2001c, 2005) lida com as diferenças entre Lévinas e Rogers. Em alguns momentos, parece que Schmid se aproveita das palavras de Rogers para ir além do que ele poderia ter dito. Entretanto, o psicólogo austríaco justifica: faz questão de ultrapassar o que Rogers possa ter compreendido quando formulou sua abordagem. Há uma grande distância entre alteridade referida por Rogers e aquela indicada pela filosofia levinasiana (Freire, 2002), extensão que não precisa ser percorrida para o bem da ACP, mas que lhe apresenta contribuições importantes. Esta diferença precisa ser mais bem esclarecida nos textos de Schmid a fim de que não se corrompa a alteridade dos textos levinasianos e rogerianos. Apesar disso, Schmid (2001a, 2005, 2006) utiliza bastante a ideia de alteridade de Lévinas.

Para Schmid (2005), é preciso que o Eu não esteja alienado do outro como verdadeiramente Outro para que ele seja pessoa em sua plenitude. A alteridade de que Schmid trata, na maioria das vezes, é um outro inalcançável, que não precisa ser compreendido, mas reconhecido em sua potencialidade. Entretanto, é preciso apontar, também, que Schmid fundamenta muitas de suas ideias na filosofia dialógica de Buber (1979), como a própria noção de reconhecimento e confirmação do Outro, enquanto que, levinasianamente, seria interessante trabalhar com a concepção de infinição em vez de confirmação. Isto significa ir em direção à diferença que há no outro e oferecer empatia, possibilitando que o cliente também caminhe nesta direção, o que não é uma necessária confirmação do que ele é. Pode ser, até mesmo, uma negação. É um risco necessário na transformação de personalidade (Worsley, 2006). Além disso, Schmid também opera com ideias como as de cooperação e colaboração entre psicoterapeuta e cliente. Todavia, é preciso considerar que tais afirmações não ocorrem a fim de estabelecer um controle por parte do profissional, mas procuram dar ênfase à relação psicoterapêutica.

Schmid (1998b) destaca que Lévinas se diferencia de Buber, também, por apresentar a figura do terceiro, ou do Outro do Outro, quebrando certa sincronia, dualidade e totalização que seria possível em uma relação a dois. Para Schmid, o terceiro nos apresenta um nós, o grupo, pois o Outro tem seus Outros e é responsável por eles. Assim, a psicoterapia não pode ser uma redoma que aparta o sujeito do mundo, mas uma forma de ajudá-lo a lidar com estas alteridades. Contudo, percebemos que a figura do terceiro ainda é pouco utilizada em todo o potencial do conceito formulado por Lévinas (1982/2007). Quando trata do terceiro homem, o filósofo chega a incluir toda a humanidade nele, requerendo do Eu uma atitude não somente ética, mas política, que visa à justiça não apenas do Outro, mas de todos os seus Outros e dos Outros destes. O mais próximo que Schmid (2012) chega disso é quando considera a psicoterapia eminentemente política, entretanto aqui ainda fala de relações grupais e pessoais, não atingindo ainda o âmbito da sociedade como um todo, com suas relações institucionais. Em Schmid, ao que nos parece, o terceiro se manifesta, principalmente, para promover relações pessoais em grupos e, assim, dar nova possibilidade ao trabalho grupal, de sorte que, para Schmid (2000), a psicoterapia de grupo deve tornar-se o carro-chefe da Abordagem Centrada na Pessoa. Aqui, a ideia de terceiro se expressa como um suplemento ainda não explorado em sua potencialidade.

\section{Considerações finais}

Apresentar uma teoria é sempre tarefa complexa, principalmente de um ponto de vista acadêmico, pois este se pretende sempre coerente e sem desvios desnecessários. Como expressão de seu autor, por outro lado, a obra é rica em contradições e falhas, que funcionam como portas abertas e caminhos por serem ainda trilhados, possibilitando novas vias de desenvolvimento do conhecimento. Apresentar a proposta teórica de Peter Schmid (2000; 2003) é também apontar caminhos inacabados e que se apresentam a nós como provocação, estradas que seguem os vestígios já lançados por Rogers (1951/1975; 1961/2009) e também por Lévinas (1982/2007; 1961/2008).

O trabalho de Schmid (2001a; 2008; 2012) deve ser considerado como um esforço em direção ao Outro verdadeiramente outro, como trata o psicólogo austríaco. Há impasses a serem superados, mas há também os que devem ser mantidos. Schmid ainda opera uma vinculação tênue entre as ideias de Buber e as de Lévinas e, vez por outra, observamos o psicólogo estabelecer uma relação de cooperação e de reciprocidade entre o Eu e o Outro; percebemos também que, na busca por enfatizar os elementos relacionais de Rogers (1961/2009), Schmid esquiva-se do diálogo com as noções individualistas que há em Rogers (1951/1975; 1977/2001), inclusive omitindo-se de lhes fazer críticas.

Como já apontamos, assim como Schmid (1998b) vê em Rogers (1961/2009) caminhos por serem trilhados, encontramos, ainda, elementos que podem e merecem ser melhor trabalhados a partir da obra de Schmid. Suas considerações acerca do processo de personalização e a interconectividade abrem espaços para a discussão de como a sociedade reconhece e lida com a alteridade das pessoas, desde que se compreenda que esta comunidade não opera somente por meio de relações pessoais (face-a-face), mas também por instituições sociais impessoais. 
Feitas estas considerações, é importante não reprovar a proposta de Schmid por sua inadequação integral ao pensamento levinasiano, pois se tratam de campos de saber diferentes. Não seria coerente transpor as palavras de um campo a outro e nem é o que o psicólogo intentou. O interessante é perceber como Peter Schmid busca na filosofia de Emmanuel Lévinas fundamentos e implicações para oferecer uma outra forma de lidar com a alteridade na teoria e na prática da ACP. Quanto a isto, consideramos que as portas e as janelas foram abertas e outras ainda estão por ser; ainda há um rastro a seguir, não necessariamente em direção à filosofia levinasiana, mas rumo a uma relação que considere, cada vez mais, o Outro em sua plenitude, e não somente o eu.

\section{Referências}

Amatuzzi, M. M. (2001). Por uma Psicologia Humana. São Paulo: Alínea.

Amatuzzi, M. M. (2010). Rogers: Ética humanista e Psicoterapia. São Paulo: Alínea.

Bezerra, M. E. S. \& Bezerra, E. N. (2012). Aspectos humanistas, existenciais e fenomenológicos presentes na abordagem centrada na pessoa. Rev. NUFEN, São Paulo, v. 4 (2), 21-36.

Buber, M. (1979). Eu e Tu. 2. ed. rev. São Paulo: Cortez, Moraes.

Castelo Branco, P. C. (2010). A Noção de Organismo no Fieri Teórico de Carl Rogers: uma investigação epistemológica. Dissertação (Mestrado em Psicologia). Universidade Federal do Ceará. Fortaleza (CE).

Cury, V. (1987). Psicoterapia Centrada na Pessoa: Evolução das Formulações sobre a Relação Terapeuta-Cliente. Dissertação de Mestrado, Universidade de São Paulo. São Paulo, Brasil.

Figueiredo, L. C. (1996). Revisitando as Psicologias. 2. ed. rev. e ampl. Petrópolis: Vozes; São Paulo: EDUC.

Freire, J. C. (1989). A Ética da Psicologia Centrada na Pessoa em Carl Rogers. Fortaleza. Dissertação (Mestrado em Educação). Universidade Federal do Ceará (UFC).

Freire, J. C. (2002). O lugar do Outro na Modernidade Tardia. São Paulo: Annablume. 2002.

Haddock-Lobo, R. (2006). Da Existência ao Infinito: Ensaios sobre Emmanuel Lévinas. Rio de Janeiro: Editora PUC-Rio/ Porto Alegre: Loyola.

Holanda, A. (1998). Diálogo e psicoterapia. Correlações entre Carl Rogers e Martin Buber. São Paulo: Lemos.

Lévinas, E. (2005). Entre Nós - Ensaios sobre a Alteridade. Petrópolis-RJ: Ed. Vozes. (Original de 1991)

Lévinas, E. (2007). Ética e Infinito: Diálogos com Philippe Nemo. Lisboa: Edições 70. (Original de 1982).

Lévinas, E. (2008). Totalidade e Infinito. Lisboa: Edições 70 (Original de 1961).
Miranda, C. S. N. (2012). Ética Radical e Psicoterapia Centrada na Pessoa: A Abertura à Alteridade Radical na Relação Terapêutica a Partir de Discursos de Psicoterapeutas sobre o Inusitado em sua Prática Clínica. Dissertação de Mestrado. Universidade Federal do Ceará.

Moreira, V. (2007). De Carl Rogers a Merleau-Ponty: A Pessoa Mundana em Psicoterapia. São Paulo: Annablume.

Moreira, V. (2010a). Revisitando as Fases da Abordagem Centrada na Pessoa. Estudos de Psicologia (Campinas), 27(4), 537-544.

Pivatto, P. S. (2003). A Questão de Subjetividade nas Filosofias do Diálogo: O Exemplo de Levinas. Veritas: Revista da Pontifícia Universidade Católica do Rio Grande do Sul, 48(2), p. $187-196$

Poirié, F. (2007). Emmanuel Lévinas: Ensaio e Entrevistas. São Paulo: Perspectivas.

Rogers, C. (1957). A Note on the "Nature of Man". Journal of Counseling Psychology, 4(3), 199.

Rogers, C. (1974). Psicoterapia e Consulta Psicológica. São Paulo: Martins Fontes, (Original de 1942).

Rogers, C. (1975). A Terapia Centrada no Cliente. São Paulo: Martins Fontes. (Original de 1951).

Rogers, C. (1977). Em Retrospecto. Quarenta e Seis Anos. In: C.R. Rogers \& Rachel Rosenberg. A Pessoa Como Centro (p. 29-46). São Paulo: E.P.U.

Rogers, C. (1983). Um Jeito de Ser. São Paulo: E. P. U. (Original de 1980).

Rogers, C. (1994) As Condições Necessárias e Suficientes para a Mudança Terapêutica de Personalidade. In: John K. Wood (Org.). Abordagem Centrada na Pessoa (p. 155-177). Vitória: Editora Fundação Ceciliano Abel de Almeida (Original de 1957).

Rogers, C. (2001). Sobre o Poder Pessoal. São Paulo: Martins Fontes (Original de 1977).

Rogers, C. (2009). Tornar-se Pessoa. São Paulo: Martins Fontes (Original de 1961).

Rogers, C. R. \& Buber, M. (2008). Diálogo entre Carl Rogers e Martin Buber. Revista da Abordagem Gestáltica, 14(2), 233-243.

Rogers, C.; KINGET, G. (1977). Psicoterapia e Relações Humanas. Vol. 1. Belo Horizonte: Interlivros (Original de 1959).

Santos, L. C. (2007). O Sujeito é de Sangue e Carne: A Sensibilidade Como Paradigma Ético em Emmanuel Levinas. Tese (Doutorado em Filosofia). PUCRS: Porto Alegre.

Schmid, P. F. (1998a). On becoming a Person-Centered Approach: A Person-Centred Understanding of the Person. In: B. Thorne \& R. Lambers, Person-centred therapy: A European perspective (p. 38-52). Londres: Sage Publications.

Schmid, P. F. (1998b) Face to Face: The Art of Encounter. In: B. Thorne \& R. Lambers, Person-Centred Therapy: A European Perspective (p. 74-90). Londres: Sage Publications. 
Schmid, P. F. (2000). 'Encountering a Human Being Means Being Kept Alive by an Enigma' (E. Levinas). Prospects on Further Developments in the Person-Centered Approach. In J. Marques-Teixeira \& S. Antunes, S. (Ed) Client-Centered and Experiential Psychotherapy (p. 11-33). Linda a Velha: Vale \& Vale.

Schmid, P. F. (2001a). Authenticity: the Person as His or Her Own Author - Dialogical and Ethical Perspectives on Therapy as an Encounter Relationship. And Beyond. In: G. Wyatt (Ed.) Rogers' Therapeutic Conditions: Evolution, Theory and Practice. Vol I: Congruence (p. 217-232). Reino Unido: PCCS Books.

Schmid, P. F. (2001b). Comprehension: The art of not knowing. Dialogical and ethical perspectives as dialogue in personal and person-centered relationships. In: S. Haugh \& T. Merry (Eds.) Rogers' Therapeutic Conditions: Evolution, Theory and Practice. Vol II: Empathy (p. 1-19). Reino Unido: PCCS Books.

Schmid, P. F. (2001c) Acknowledgement: The art of responding. Dialogical and Ethical Perspectives on the Challenge of Unconditional Relationships in Therapy and Beyond. In: J. Bozarth \& P. Wilkins (Eds.) Rogers' Therapeutic Conditions: Evolution, Theory and Practice. Vol III: Unconditional Positive Regard (p. 155-171). Reino Unido: PCCS Books.

Schmid, P. F. (2003). The Characteristics of a Person-Centered Approach to Therapy and Counseling: Criteria for identity and coherence. Person-Centered \& Experiential Psychotherapies, 2(2), 104-120.

Schmid, P. F. (2005). Authenticity and alienation: Towards an understanding of the person beyond the categories of order and disorder, in: Steven Joseph \& Richard Worsley (Eds.), Psychopathology and the person-centered approach (p. 75-90). Ross-on-Wye: PCCS Books.

Schmid, P. F. (2006). The Challenge of the Other. Towards dialogical person-centered psychotherapy and counseling. Person-Centered and Experiential Psychotherapies, 5(4), 241-254.

Schmid, P. F. (2008). A Personalizing Tendency. Philosophical Perspectives on the Actualizing Tendency Axiom and its Dialogical and Therapeutic Consequences, in: Brina Levitt (Ed.), A Positive Psychology of Human Potential. The person-centered approach (p. 84-101). Ross-on-Wye: PCCS Books.

Schmid, P. F. (2012). Psychotherapy is Political or it is Not Psychotherapy: The Person-Centered Approach as an Essentially Political Penture. Person-Centered \& Experiential Psychotherapies, 11(2), 95-108.

Vieira, E. M. \& Freire, J. C. (2006) Alteridade e Psicologia Humanista: Uma Leitura Ética da Abordagem Centrada na Pessoa. Estudos de Psicologia (Campinas), 23(4), 425-432.

Vieira, E. M. (2009). Sobre a Proposta de Conhecimento Presente na Teoria Rogeriana, ou da Sabedoria Residente na Ignorância. Rev. NUFEN (UFPA), 1(2), 4-19.

Worsley, R. (2006). Emmanuel Levinas: Resource and challenge for therapy. Person-Centered \& Experiential Psychotherapies, 5(3), 208-220.
Iago Cavalcante Araújo - Mestre em Psicologia pela Universidade Federal do Ceará, Professor do Curso de Psicologia da Faculdade Metropolitana da Grande Fortaleza (FAMETRO) e do Curso de Psicologia da Faculdade de Tecnologia Intensiva (FATECI).E-mail: iagopsi@gmail.com

José Célio Freire - Psicólogo, Mestre e Doutor em Psicologia, Professor Titular do Curso de Psicologia e do Programa de Pós-Graduação em Psicologia da Universidade Federal do Ceará (UFC). Endereço Institucional: Universidade Federal do Ceará, Centro de Humanidades, Departamento de Psicologia. Rua da Universidade (Benfica).

Recebido em 24.11.2016

Primeira Decisão Editorial em 31.03.2017

Aceito em 07.05.2017 